\title{
La mediación y la visión positiva del conflicto en el aula, marco para una pedagogía de la convivencia
}

\section{The mediation and positive view of the conflict in the classroom: Framework for a pedagogy of coexistence}

\author{
Olga Elena Suárez Basto* \\ Universidad Santo Tomás, \\ Bogotá
}

Recibido: 15 de octubre de 2007

Revisado: 7 de diciembre de 2007

Aceptado: 22 de enero de 2008

\section{Resumen}

En el presente artículo se ofrece un marco de reflexión que tiene como propósito destacar la importancia, para el ámbito escolar, de la gestión del conflicto en forma positiva desde la pedagogía para la convivencia y la mediación transformadora. Es claro que el conflicto es inherente al ser humano, pero la convivencia también, y éste forma parte de la convivencia; por tanto, es fundamental e ineludible promover una comprensión del conflicto como fuente de aprendizaje, desarrollo y maduración personal, que en una sociedad democrática que se rige por el diálogo y la tolerancia, encuentra su espacio y ámbito de expresión. Formar, promover y fomentar las actitudes que hacen del conflicto una oportunidad de desarrollo, representa una visión contemporánea de la educación y significa una oportunidad de cambio para la sociedad.

Palabras clave: conflicto, pedagogía, mediación transformadora, aula de clase, diálogo, convivencia.

\section{Abstract}

This article presents a framework of reflection which purpose is to stand out the importance, for the school field, of the conflict procedure in a positive

* Correspondencia: Olga Elena Suárez Basto, psicóloga, magíster en Evaluación en Educación, docente Facultad de Psicología, Universidad Santo Tomás. Dirección postal: cra. 9 № 51-11, Bogotá, Colombia. Correo electrónico: olgasuarez@correo.usta.edu.co; oesb_520@hotmail.com. 
way from the pedagogy in order to coexistence, since transforming mediation. Is clear that the conflict is inherent to the human being, but the coexistence too and this it's part of the coexistence, therefore, is essential and unavoidable, to promote an understanding of the conflict, as a source of learning, development and personal growth that in a democratic society which it's regulated by dialogue and tolerance, it founds its space and expression field. To form and promote the attitudes that makes from the conflict a development opportunity, it represents a contemporary view of education, and it means a change opportunity for the society.

Key words: conflict, pedagogy, transforming mediation, classroom, dialogue, coexistence.

\section{Qué se entiende por conflicto escolar: un breve marco de referencia}

El aula de clase y su contexto, en el momento histórico actual, no es siempre el espacio de convivencia deseado para nuestros estudiantes; en ella se organizan y planifican la influencia curricular y la no curricular con el objetivo no solamente de recrear conocimiento, sino también, de gran manera, para construir valores de convivencia, de solidaridad, de aceptación del otro en la diferencia, del diálogo entre los sujetos y del sentido de comunidad. No obstante, la escolarización dejó de ser la única propuesta, después de la familia, de formación y educación de la personalidad. Los mensajes que en ella se transmiten, se reconceptualizan y se producen son motivo de debate por su credibilidad, legitimidad y viabilidad, para determinados estudiantes, padres de familia y docentes. La repercusión práctica de ello tiene naturaleza diferente y afecta a distintas facetas de la convivencia humana.

El ser humano, de acuerdo con lo anterior, tiene una naturaleza convivencial, pero ello no niega que las relaciones sociales puedan deteriorarse; en otras palabras, de la misma coexistencia emergen de manera inherente los conflictos en las relaciones humanas que se suscitan en cualquiera de los escenarios de interacción social. Así: "Toda relación social contiene elementos de conflicto, desacuerdos e intereses opuestos. La escuela es una organización y como tal su funcionamiento no puede ser entendido sin considerar la significación del conflicto" (Ovejero, 1989).
Los desacuerdos, las tensiones interpersonales, los enfrentamientos intra o intergrupales, los antagonismos, las hostilidades son propios de la naturaleza humana; no obstante, si los elementos del conflicto emergen del diálogo, éste podría ser nuestra mejor opción para trabajar sobre las realidades contenciosas. Sin embargo, como todos los procesos dialógicos, no son útiles para reducir la posible hostilidad, conflicto, o agresión. La intención de este escrito es reforzar la postura de comprender el conflicto como una oportunidad transformadora de gran utilidad para dirimir y generar constructos de realidades comunes y consolidadoras que apunten al restablecimiento de la convivencia y a prácticas culturales más frecuentes de intercambio pacífico.

Para efectos de iniciar una comprensión acerca de los conflictos en el aula y el papel preponderante del mediador en el mismo, es necesario adentrarnos en una conceptualización que nos permita aclarar cómo entendemos el conflicto en el aula de clase. En primer lugar, es menester afirmar que en nuestro medio existe la marcada tendencia a utilizar indiscriminadamente los términos conflicto y violencia como si se tratase de una misma situación. La fuerte incidencia del conflicto armado en nuestro desarrollo sociopolítico y cultural es absolutamente absorbente. Los medios de comunicación y aun el mismo esquema de enseñanza tradicional han promovido de manera permanente una percepción ambigua de conceptos tales como "la sociedad de la violencia", "los hijos de la violencia", "la cultura de la violencia"; estas son algunas de las acepciones que con frecuencia se acuñan en los discursos 
sociales, tratando de imprimir a nuestro carácter un sentido eminentemente violento, vandálico, agresivo, pendenciero y disruptivo, como si se tratase de una condición inherente a nuestro propio comportamiento. Ello hace necesario los dos términos:

No es legítimo asociar conflicto con violencia, porque mientras el conflicto responde a situaciones cotidianas de la vida escolar, en la que se dan enfrentamientos de intereses, discusión y necesidad de abordar el problema, la violencia es una de las maneras de enfrentarse a esa situación (Etxeberría, Esteve y Jordan, 2001, p. 82).

Dentro del conflicto se enmarcan las divergencias, las disputas, las controversias, los objetivos incompatibles $\mathrm{y}$, en forma excluyente, los antagonismos, los intereses entre las partes y muchos más; sin embargo, éstos son propios de la interacción humana. El conflicto es obvio en la sociedad pero no la violencia, por lo que el conflicto no necesariamente debe terminar en violencia. Por ello, la manera de abordar el conflicto y los mecanismos de resolución condicionan su desenlace; si se maneja el conflicto con la naturalidad propia que lo genera, se están incorporando la creatividad, la innovación y las ideas que conducirán a que cuando surja se puedan canalizar todas las opciones de las partes intervinientes en la búsqueda de una solución que no origine violencia. Cuando el conflicto no es capaz de solucionarse, o al menos de transformarse, genera frustración; por ende, es previsible que se desaten comportamientos agresivos y violentos.

Existe, por lo anterior, una relación entre conflicto y violencia, pero no es bidireccional. Se puede afirmar lo siguiente:

La violencia siempre va acompañada de nuevos conflictos, pero el conflicto no siempre entraña situaciones de violencia, pues los seres humanos disponemos de un amplio abanico de comportamientos con los que poder enfrentarnos a las situaciones de confrontación de opinio- nes e intereses con los otros sin necesidad de recurrir a la violencia (Hernández, 2002).

El proceso de socialización es el proceso por el que aprendemos a vivir con el conflicto y a regularlo de manera que depare el máximo de bienestar para nosotros mismos y para los demás. La concepción positiva del conflicto deviene de entender el mismo como elemento intrínseco del proceso de socialización, ya que es parte del proceso de interacción social, en el que personas, grupos y especie establecen relaciones y se transmiten anhelos y expectativas. De la optimización y manejo adecuado del conflicto emergen las alternativas que permiten que éste no se convierta en agresión y violencia.

El conflicto supone la pugna entre personas o grupos interdependientes que tienen objetivos incompatibles o aparentemente percepciones incompatibles. En este sentido

El conflicto conjuga los fines y las pretensiones individuales y sociales que persiguen los individuos (o los grupos). Cada contrario, dentro de sus expectativas y formas de abordar las controversias, genera interpretaciones propias de los que esta en disputa. Esta perspectiva (personal o grupal) puede dificultar o facilitar el tránsito hacia puntos de entendimiento o contradicción que facilitan la construcción de alternativas y parámetros de entendimiento o pueden agudizar la controversia mediante la asunción de posicionamientos contrastantes. $\mathrm{Si}$ al conflicto se le imprime una visión positiva, las diferencias se resolverán mediante la apertura y búsqueda de instancias que permitan a los interlocutores interactuar a través del dialógo, la reflexión y el entendimiento.

Ahora bien, la violencia podría entenderse como la forma oscura e inadecuada de enfrentarse a los conflictos, recurriendo al poder, la imposición y la anulación de los derechos del otro para salir proclamado vencedor en el enfrentamiento. La 
violencia no puede negociarse, no pueden establecerse acuerdos sobre el tipo de violencia que está permitida y el tipo de violencia que resultará condenada en un centro escolar; no puede justificarse cuándo está bien o mal empleada, la violencia debe ser rechazada de plano por la comunidad escolar como medio de resolución de conflictos. No es dable permitir desde ningún punto de vista la réplica de la metáfora del "conflicto armado en la vida escolar"; por el contrario, la postura que asumiremos nos permitirá manejar y gestionar el conflicto en forma positiva: se contempla la posibilidad de negociar, conscensuar, establecer acuerdos, compromisos, generar empatía con el otro, comprender su postura y conciliar con sus razones, etc.

Como se ha dicho, el conflicto es propio de la naturaleza del ser humano; forma parte de su existencia, de su estructura básica que le permite madurar y desarrollarse como persona y como sistema humano. El conflicto es un espacio humano, que no podemos destruir o desaparecer de la realidad escolar. En estas condiciones podemos afirmar que el conflicto es inevitable, a la vez que es necesario en la vida de las personas; forma parte de la convivencia humana y constituye una fuente de aprendizaje, desarrollo y maduración personal, ya que la persona debe poner en marcha una serie de mecanismos que favorezcan una gestión positiva del mismo. Se puede afirmar, entonces:

Es verdad que a menudo el conflicto crea tensión, ansiedad y molestia, pero como el enfado, estos sentimientos en sí mismos no siempre son malos. Pueden proporcionar el tire y afloje necesario para el desarrollo y el crecimiento. Creemos que el conflicto en el aula puede proporcionar una tensión creativa que sirva para inspirar la solución de problemas y para motivar la mejora del rendimiento individual o grupal... constituye un paso necesario hacia el aprendizaje personal y hacia el proceso de cambio (Schnuck y Schnuck, 1983, en Ovejero, 1989, p. 274).
En este mismo sentido alude Johson (1979, p. 301 en Ovejero, 1989), "que el conflicto en el aula no sólo es inevitable sino que incluso es necesario para combatir la rutina escolar y así facilitar el progreso en la escuela". En esta misma perspectiva, Peiró añade que el conflicto posee tantos aspectos funcionales como disfuncionales: "En realidad, la funcionalidad o disfuncionalidad de una determinada conducta depende siempre de poscriterios adoptados y de la perspectiva considerada. Algo funcional para la organización puede ser disfuncional para algunos miembros $y$ viceversa" (Peiró, 1985, Vol. II, p. 481, en Ovejero, 1989).

El ser humano se encuentra inmerso en organizaciones de diverso orden, desde microorganizaciones como la familia hasta macroorganizaciones como la misma sociedad. En esta interacción el individuo despliega su conducta que se manifiesta en pensar, sentir, transmitir, emprender, experimentar, comunicar e inventar continuamente nuevas realidades y situaciones. La forma de manejar y percibir las cosas y la vida en la individualidad, o en grupo, genera puntos de vista y perspectivas particulares que no siempre están acordes con las expectativas y miradas que nuestros congéneres hacen de esa misma realidad. Los puntos de vista divergentes con frecuencia generan conflictos, que a la postre los podemos optimizar y potencializar de modo que los convirtamos en ventajas que contribuyan a cocrear escenarios que generen convivencia, cohabitación y cooperatividad. En este contexto, los conflictos se convierten en un vehículo para inventar, imaginar, aprender y comunicar. No obstante, la visión del conflicto no siempre es tan optimista, más aún tratándose de un país marcado por el conflicto violento como el nuestro. En tal sentido, Ortega afirma:

Existe una demonización del conflicto que los asocia indiscriminadamente a conductas no deseables, a veces delictivas. Pero el conflicto es también confrontación de ideas, creencias, valores, opiniones, estilos de vida de vida, pautas de comportamiento, etc. Que en una sociedad democrática que se rige por 
el diálogo y la tolerancia, encuentra su espacio y ámbito de expresión (Ortega, 2001, p. 10).

En una sociedad que asocia con demasiada ligereza el conflicto con la violencia y sus diversas formas de expresión, hay que tener en cuenta algunas distinciones. Nosotros partimos de que el conflicto es un fenómeno normal y no necesariamente negativo; que posee una serie de potencialidades positivas que sirven para fortalecer aquellas relaciones que nos importan. La expresión de la violencia en el tratamiento de un conflicto suele erradicar esas potencialidades positivas, dando lugar a la ruptura en muchos casos y a una espiral de violencia, en otros. En estas situaciones no solo perdemos la oportunidad de aprender éticamente y profundizar en la relación a través de un proceso constructivo, sino que deterioramos el clima de convivencia; en este aspecto, el conflicto es una oportunidad para un proceso de búsqueda conjunta de soluciones y de negociación, que se convierte en una interacción que estimula la reflexión ética del comportamiento humano.

Por lo anterior, acogemos la perspectiva según la cual los conflictos, en tanto oportunidades para aprender, son necesarios para el crecimiento personal y comunitario, pues ayudan a la diferenciación individual, así como al desarrollo de habilidades fundamentales para el aprendizaje y la convivencia ciudadana (Colectivo Amani, 1994).

Aceptar el conflicto como algo natural, como expresión inevitable de los individuos o de los grupos, visto desde la perspectiva de la opción para cocrear nuevos discursos de convivencia y cohesión social basado en la mutualidad y fundado en la aceptación de diferencia con el otro, constituye asumir un enfoque socioconstruccionista de la comprensión positiva del conflicto (sentir que se asume en este escrito).

Los nuevos paradigmas en resolución de conflictos se asientan en la comunicación y las prácticas discursivas y simbólicas que promueven diálogos transformadores. En concordancia, Dora Schnitman comenta:
Como prácticas de resolución alternativa de conflictos, expande el foco desde los intereses a las formas de intercambio a partir de las cuales puedan emerger acciones significativas para los participantes. Entienden que si el significado se genera a través de relaciones, entonces ser responsable hacia un proceso relacional consiste en favorecer prácticas comunicativas específicas que incrementan la inteligibilidad del diálogo, el reconocimiento y la recuperación del poder (empowerment) de los participantes, para avanzar hacia un futuro posible, dando los pasos capaces de conducir a él (Schnitman, 2000, p. 25).

Esta construcción colaborativa de nuevas realidades se fundamenta en el diálogo transformador que surge de la interacción y permite reconocer las pautas que se generan entre las personas 0 los grupos, lo cual facilita identificar los dilemas, los recursos, las potencialidades y alternativas de acción.

Entiéndese la evolución de un conflicto enfocando no sólo las emociones, intenciones y creencias de los participantes -o sus intereses- sino los dominios simbólicos, narrativos y dialógicos como el medio en que se construyen y transforman significados y prácticas, y surgen identidades, mundos sociales y relaciones emergentes (Schnitman, 2000, p. 26).

Se presume que en este proceso entran en juego las competencias comunicativas; la comunicación entre las personas es el soporte de la interacción, por eso si ésta resulta distorsionada o bloqueada, la resolución del conflicto puede darse en forma violenta o pasiva. La educación para el desarrollo integral y autónomo de los individuos debe partir de una concepción positiva del conflicto, como proceso lógico que se presenta en cuanto intentamos hacer una tarea común a causa de la diversidad humana. 
El conflicto trae consigo posiciones que resultan antagónicas y en apariencia irreconciliables, lo que eventualmente hace que los actores asuman posturas radicales que impidan la posibilidad de la interacción fundada en el diálogo y en la reconciliación. Es probable que estas posturas imposibiliten la búsqueda de iniciativas y polaricen de manera extrema la viabilidad del dialogo. Ello invita a que de modo preponderante emerja la figura del mediador, como instancia que libera la disposición hacia el diálogo y motiva las posibilidades para construir escenarios de concertación. Por ello, es claro que del conflicto emergen en forma fundamental la mediación y sus efectos potencialmente transformadores; por tanto, el papel del mediador en este ámbito tiene gran importancia. A propósito, la autora Dora Schnitman, afirma:

Una característica importante en el movimiento interno en el conflicto es el valor otorgado a la mediación, entendida como un trabajo colaborativo en contexto, para encontrar oportunidades y condiciones de cambio (Schnitman, 2000).

El rol del mediador se enmarca en la búsqueda de las oportunidades que surgen durante el proceso, en la compresión de las perspectivas de los otros y en la forma de revertirlas a manera de empoderamiento para las partes, el reconocimiento recíproco de los participantes, la consecución conjunta de los recursos, de las acciones transformadoras, de las potencialidades concertadas de los contendientes, de la potencialización dialógica de las partes y de la búsqueda de apoyar las perspectivas, opiniones y experiencias de ellas para coconstruir verdaderas y reales alternativas de decisión para la resolución del conflicto.

A través de la conversación el mediador opera para facilitar esas condiciones, pero prescinde de su propia calificación respecto de los temas, contenidos, soluciones, y su postura viabiliza el entramado de las relaciones, sin entrar en el "juego del conflicto". Una herramienta fundamental es el énfasis en los intercambios comunicativos.
La negociación y su contrapartida, la mediación, son intercambios comunicativos en los que las partes en conflicto tratan de determinar "qué dará y recibirá cada uno, o que hará o tomará, en sus transacciones mutuas" (Rubin y Brown, 1975, p. 1).

La mediación es una extensión de la negociación. El mediador o el equipo mediador representa a una tercera parte "neutral" que facilita el proceso de negociación y deja a las partes la responsabilidad de acordar una solución. Por ello, en este aparte, y vale la pena retomar la importancia de resaltar el diálogo en el caso concreto de la mediación.

Bohm (1996) recuerda que "dia-logos", no se refiere a "dos" sino a "a través de". Diálogo es un término que alude a la cocreación de significados a través de -y entre- cierto número de interlocutores. La comunicación no es un vehículo para la transmisión de información, sino un proceso constructivo.

Bakhtin (1986) destaca la capacidad del diálogo para construir sentido al señalar que en toda comprensión las personas responden activamente a un "otro"; un diálogo involucra "comprensión activa". Quien escucha no sólo lo hace para decodificar una elocución sino que al mismo tiempo capta a quién va dirigida, la relaciona con su propia trama compleja de intereses y supuestos, e imagina cómo responde la elocución a futuras elocuciones de posibles interlocutores y a qué tipo de respuestas invita, la evalúa e intuye cómo podrían comprenderla otros.

El diálogo permite pensar en algo no pensado, escuchar algo no escuchado, decir algo no dicho; será posible obtener nuevas formulaciones o producciones en donde se pueden considerar nuevas perspectivas, es decir, recontextualizar (encontrar nuevos significados); al resignificarse se obtienen relatos diferentes y se reformulan los conflictos por lo que, la mediación resulta ser un encuentro comunicativo $\mathrm{y}$, desde la visión narrativa, un proceso comunicacional que invita a nuevas metáforas de la vida. 
El interés de este artículo se centra en dos aspectos que a nuestro juicio resultan relevantes y prácticos. El primero atañe al desarrollo de los principios básicos de una pedagogía convivencial que estaría dirigida a contrarrestar y prevenir los factores de violencia o conflicto en la educación y que tienen la intención de fomentar escenarios claves como marco para el desarrollo de una pedagogía para la convivencia y la paz, y, en segunda instancia, lo pertinente a la mediación vista desde un criterio transformador, desde una pedagogía propositiva constructivista.

Las estrategias y habilidades para la transformación de conflictos en el marco de la mediación en el aula escolar se encuadran dentro de una pedagogía comprometida con la vida ciudadana de carácter democrático y participativo. Propiciar en el contexto escolar escenarios y estructuras que generen procesos de mediación, de negociación, y fomentar las actitudes que hacen del conflicto una oportunidad de desarrollo, representa una visión contemporánea de la educación.

Este tipo de educación promueve un marco de relaciones fundamentadas en el valor de la diferencia, en el respeto por el otro y con el otro, que a su vez se repliquen y conciten un cambio en los ámbitos de la vida cotidiana de la escuela. Se debe pensar que hacia el futuro, el cambio debe reflejar el porvenir de las interacciones en la vida, en los órdenes profesional, familiar y social; en síntesis, se trabaja no sobre los problemas, sino sobre las soluciones y esperanzas de un porvenir más humano y comprensible.

Los principios de la pedagogía para la convivencia bien pueden tomarse según el resumen que podemos hacer de la autora Mireia Uranga Arakistain (2007), los cuales fomentan los siguientes aspectos:

1. El uso del diálogo. El desarrollo de la capacidad dialógica promueve la disposición hacia la comunicación. En este aspecto, el diálogo se caracterizará por un intercambio y enriquecimiento de ideas a través de un proceso de escucha activa, de empatía, de apertura hacia el otro y de disposición para cuestionarse las ideas sin evitar rebatir las del otro: "Así, para que el diálogo tenga éxito, es decisivo que uno pueda hacer escuchar su voz. Parafraseando la lógica: 'Si no expreso cuál es mi posición, lo que verdaderamente pienso, no hay diálogo' ". (Gergen, 1994). Para el desarrollo de este importante aspecto, es necesario acoger la perspectiva de Gergen, frente a lo que denomina el diálogo transformador, que en esencia es facilitar la construcción colaborativa de nuevas realidades por parte de los intervinientes en el conflicto.

2. El aprendizaje cooperativo. El objetivo es que el estudiante perciba y apropie que obtener sus metas no lleva a que sus compañeros o compañeras fracasen; al contrario, en la medida en que el grupo avance como colectivo, él como individuo avanzará. Ello no representa negar la competitividad, sino estimular las diferentes dimensiones que encontramos en ella. Es procedente situar procesos competitivos en marcos cooperativos.

3. Solución de problemas. Los estudiantes, los padres de familia, los docentes, los administrativos y los orientadores deben aprender a generar recursividad y alternatividad para buscar soluciones propias, no siempre a través de alguien a quien atribuimos autoridad o conocimiento. Es un aprender a pensar significativa y críticamente y a ser creativos con la resolución de los problemas que surgen en la interacción. Algunos de los pasos que contribuyen a este proceso son crear el clima, definir y discutir el problema, explorar todas las opciones enriqueciéndolas con los diversos puntos de vista de los participantes, valorar todas las alternativas, etc.

4. Afirmación. Se trae a colación el fortalecimiento de las habilidades de las personas para desarrollar comportamientos aceptables socialmente, como la autorregulación, la autoestima y la autodisciplina, como beneficios adicionales fruto de desarrollo de las habilidades de comunicación y solución de 
problemas. Los disputantes participan activamente y toman decisiones sobre los problemas a los que se enfrentan. Esto fomenta la autoconfianza, la autoafirmación y la autorregulación. Instrumentar este tipo de destrezas y habilidades es fundamental, en aras de crear una cultura preventiva del conflicto; no obstante, es clave, que las personas, además de manejar sus propias experiencias vitales $y$ sentimientos, conozcan en el fragor del conflicto la manera de reconocer y encontrar la importancia de la expresión del otro como mecanismo que permita presentarle nuestro apoyo y acuerdo a través de la reafirmación. Reafirmar es conceder valor, respetar la validez de mi subjetividad. Por tanto, no basta con generar afirmación de algunos valores personales, sino que los mismos se pueden transferir y reconocer en el otro.

5. Gestión democrática en el aula. La escuela es uno de los contextos más importantes de socialización de los estudiantes y es la cantera de ideas y percepciones acerca de principios y conceptos tan fundamentales como la sana convivencia, la armonía, la justicia, la equidad, la democracia, etc. El proceso consiste en involucrar a los estudiantes, en forma activa y actuante, en las decisiones y consensos que se derivan de la vida escolar. Ello conlleva implícitamente la aceptabilidad de las normas y preceptos que garantizan la convivencia y las responsabilidades dentro de la comunidad educativa.

6. Apertura y empatía. Consiste en fomentar la actitud de estar abierto a lo que otra persona expresa y desea, "el ponerse en los zapatos del otro", el promover la posibilidad de experimentar cómo cada uno ve diferentes aspectos de una misma situación y sentir que la opinión del otro es tan importante y respetable como la personal, en razón de que nos brinda una mirada diferente que nos enriquece.

7. Comprensión y manejo de la agresividad y la violencia. Se debe distinguir entre agresivi- dad y agresión, presumiendo que la agresividad exige aprender a manejarla para que no se traduzca en agresión y, por tanto, en violencia. No se trata de desconocer la violencia como un hecho cotidiano latente y evidente, sino que el estudiante asuma una actitud crítica y constructiva frente a sus causas y sus efectos.

8. Promoción de modos de confrontación no violentos. Se debe socializar permanentemente que la confrontación es uno de los modos necesarios para tratar un conflicto, indicando para ello que el enfrentamiento es parte de la interacción social y que por tanto cada persona debe ser leal, honrada y pacífica, como herramientas para obtener constructos de convivencia.

9. Corresponsabilidad. La resolución de los conflictos debe residir, en esencia, en las partes directamente involucradas en el mismo, pues de esta manera se garantiza que la salida al conflicto sea aceptada, sostenida y desarrollada por las partes. En este aspecto surge en forma relevante el sentido de la mediación.

10. Educación en valores. Cualquier propuesta para la gestión positiva de los conflictos debe pasar necesariamente por una educación en valores, donde se forme al estudiante en el reconocimiento de la dignidad de toda persona, en el derecho a la ciudadanía y a su ejercicio, en la deliberación y la participación por el interés común de una convivencia sana en la vida escolar. En resumen, se pretende que los estudiantes adquieran contenidos mínimos de una educación cívica pertinente.

Los anteriores principios deben llevarse a la práctica, para lograr el desarrollo de habilidades que permitan un ambiente de armonía y convivencia dentro del aula. No se pretende que los anteriores principios sean aceptados como principios determinantes; es probable, y esa es la intención, que los mismos se afinen y se enriquezcan para consolidar la cultura de la convivencia en el ámbito educativo. 
Desde una orientación teórica basada en el construccionismo social y una gama de prácticas coherentes con ella, nuestro concepto del diálogo transformador pone especial acento en la responsabilidad relacional, la expresión personal, la reafirmación del otro, la coordinación, la autorreflexividad y la cocreación de nuevas realidades.

\section{Sobre las competencias del mediador orientador, desde la práctica del enfoque transformador}

Para el desarrollo de este apartado, consideramos fundamental partir de:

la cosmovisión de comprender el conflicto como potencialmente transformador, esto es, que ofrece a los individuos la oportunidad de desarrollar e integrar sus capacidades tanto para fortalecerse así mismos como para empatizar con los demás. Al concretarse estas capacidades, se da un paso significativo hacia la transformación individual y social, porque la fuerza del ser humano individual y el sentido de conexión y de comunidad se desarrollan conjuntamente (Bush y Folger, 1994, p. 74).

Esta estrategia resulta ostensiblemente útil para sacar provecho de las oportunidades que ofrece el conflicto para la autodeterminación (la recuperación del propio poder) y la empatía (el conocimiento del otro).

Referenciado lo anterior, hay que reseñar cuáles son las competencias con que debe contar un mediador desde el enfoque transformador. Según Bush y Folger, (1994), se precisan las siguientes:

1. Describir el papel y los objetivos del tercero en lo referente a recuperación del poder y reconocimiento. En la práctica transformadora, el mediador puntualiza que su objetivo es crear un contexto que ayude y aliente a las partes a clarificar sus objetivos, recursos y preferencias para la toma de decisiones por sí mismos respecto de la situación.

2. No sentirse responsable por los resultados de la mediación. En un marco transformador, el mediador es consciente de su responsabilidad en establecer y mantener un contexto adecuado para los esfuerzos que realicen las partes en su proceso de deliberación, toma de decisiones, comunicación y adopción de perspectivas. El mediador rechaza en forma deliberada su sentimiento de responsabilidad en la generación de acuerdos, la resolución de los problemas de las partes, el alivio de sus dificultades o su reconciliación. Sólo tendrán valor real y verdadero las decisiones y cambios que las partes asuman libremente por sí mismas. Transferir la toma responsable de decisiones a las partes es una característica primordial de la práctica transformadora.

3. Negarse conscientemente a emitir juicios sobre las opiniones y decisiones de las partes. Es relevante dentro de la práctica transformadora que el mediador rehúse asumir una posición crítica o emitir juicios frente a las opciones o decisiones de las partes disputantes. La autoconciencia, el control y la suspensión de los juicios de valor son esenciales en esta práctica. Las acciones del mediador son una "respuesta" adecuada a los pasos que van tomando los disputantes porque el proceso es guiado por el criterio de éstos.

4. Adoptar una visión optimista de la capacidad y las motivaciones de las partes. La manera como la tercera parte considera en forma optimista las capacidades y motivaciones de las partes disputantes es una característica de la práctica transformadora. Las terceras partes que instrumentan este enfoque se muestran siempre optimistas frente a la idoneidad de los disputantes y su capacidad para mejorar por sí mismos su situación en sus propios términos. 
5. Permitir y ser sensibles a la expresión de emociones de las partes. En la práctica transformadora, los profesionales intervinientes consideran la expresión de las emociones (ira, dolor, frustración, etc.) como parte integral del proceso del conflicto. Los mediadores permiten que las partes manifiesten sus emociones y las liberen, y están preparados a trabajar con las expresiones a medida que se despliega el conflicto. Oprimir, eludir o desestimar la expresión de las emociones equivale a ignorar las oportunidades para la recuperación de poder y el reconocimiento que esas circunstancias suelen presentar. La manifestación de los sentimientos no se da para librarse de ellos, sino que se optimiza para reencauzarlos y establecer qué hay detrás de ellos para contribuir a la recuperación del poder y el reconocimiento.

6. Permitir y explorar la ambigüedad de las partes. Con frecuencia, las partes contendientes no tienen claridad frente a los temas en discusión, en relación con lo que quiere cada cual del otro y finalmente hacia la construcción genuina de su postura. Para el mediador transformador, éstas son situaciones que brindan una clara oportunidad para la recuperación del poder, por ello es fundamental que el mediador permita, facilite y aun estimule que las partes profundicen las fuentes de su ambigüedad, confusión o incertidumbre.

7. Permanecer focalizado en el aquí y ahora de la interacción en torno del conflicto. El mediador se centra en la atención a cada alusión que los disputantes hacen (verbales o no verbales) sobre cómo quieren que se les considere, qué es lo importante para ellas, por qué son relevantes específicamente esas cuestiones, cuáles son sus opciones preferidas, etc. El mediador focalizado puede discernir y analizar qué puntos tienen imprecisos las partes, cuáles alternativas se les presentan, en qué aspectos se sienten incomprendidos o alguno de ellos ha malinterpretado a la otra parte. En consecuencia, precisar cada uno de los puntos que sirven para brindar posibilidades tendientes a la recuperación del poder y el reconocimiento es una labor fundamental del mediador transformador.

8. Ser sensible a las formulaciones de las partes sobre hechos del pasado. Una excelente manera de lograr los objetivos de recuperación del poder y el reconocimiento consiste en estimular a los disputantes para que hablen sobre sucesos del pasado que tengan relación directa con el conflicto. Propiciar el abordaje de debate sobre el pasado es una estrategia de sentar las bases de estos intercambios presentes y permite que las partes, sin incurrir en presionarlas, reexaminen y revisen sus ideas acerca del pasado y hagan extensivo su reconocimiento a la otra parte. Cuando los disputantes revisan su pasado con frecuencia toman conciencia de las elecciones que decidieron en diversos puntos de su evolución y se lo revelan a sí mismos y al otro. Advierten que hubo momentos decisivos desaprovechados y se percatan de los recursos y opciones que en otro momento tuvieron y que dejaron pasar inadvertidos. Esta situación lleva a los disputantes a modificar la idea que tienen de sus recursos, opciones y capacidades actuales, aspecto que implica de manera preponderante avanzar hacia el reconocimiento y la recuperación del poder. Explorar el pasado fundamenta un valor que tiene incidencia directa en el presente, particularmente por las oportunidades que brinda a las partes para aclarar sus opciones, y para revisar y modificar la percepción que cada uno tiene de la otra parte.

9. Ver la intervención como un punto en una secuencia más amplia de la interacción del conflicto. El conflicto es un proceso y en la misma medida lo es la intervención, por lo que es necesario que el mediador tome conciencia de los ciclos que posiblemente atraviese el conflicto. Es claro que una sola intervención no basta para abordar en su totalidad todos sus aspectos; en consecuencia, es necesario que el mediador comprenda que su 
visión puede ser "a largo plazo". Ello implica que su intervención se desarrolla dentro de un marco temporal mayor. En este aspecto es importante reconocer que incluso el hecho de llegar a un acuerdo no es lo mismo que ponerlo en práctica. Los terceros transformadores dejan que sobrevengan los ciclos y hasta les dan bienvenida como ulteriores momentos de deliberación y de recuperación de poder".

10. Experimentar una sensación de éxito cuando se aprecia aunque sea un mínimo grado de recuperación de poder y reconocimiento. Este aspecto apunta a las satisfacciones profesionales que obtienen los profesionales con una práctica transformadora, durante las sesiones, cuando se ponen de manifiesto las oportunidades para la toma de poder y el reconocimiento, y pueden ayudar a las partes a incrementar su fortaleza y capacidades personales y a mejorar su comprensión de las interrelaciones. En este aspecto el éxito no se logra por haberse concertado un acuerdo final; por el contrario, valoran el nexo existente entre los pequeños logros y los grandes compromisos. Finalmente, si no se logra ningún acuerdo entre las partes, el mediador está en la capacidad de comprender que aun después de la intervención las partes pueden adquirir compromisos de acción si efectivamente durante el proceso se presentaron avances reales en el sentido de la recuperación de poder y reconocimiento.

Desde la perspectiva de constituirse en orientador como un consultor interno de procesos de mediación, bien puede, para cumplir con este rol, crear escenarios para facilitar procesos reflexivos en torno a la convivencia humana y a sus dilemas y conflictos. En este sentido, podemos utilizar las siguientes reglas que viabilizan la creación de estos contextos.

En el ejercicio de consultoría, la definición de las reglas de trabajo con el colectivo es básica: ayuda a definir y a darle forma y sentido a la participación de todas las personas.
Reglas propuestas por el colectivo; reglas para desarrollar convivencia y bienestar; reglas de equidad, posibilitadoras de diálogo, el acercamiento, el intercambio y la reflexión en igualdad de condiciones; reglas entendidas no en términos restrictivos sino generatrices, es decir, reglas que inviten a crear.

La explicitación de las reglas nos permite establecer unas condiciones democráticas y saludables mínimas para construir el conocimiento necesario en los procesos de transformación. Las reglas van a definir el tipo de vínculos y la naturaleza de las relaciones.

\section{El respeto}

El respeto por el otro, por sus puntos de vista (no hay miradas ni verdades únicas), así como el derecho a hablar o permanecer en silencio.

\section{El reconocimiento de múltiples saberes}

Ningún conocimiento es menos valioso que los demás.

\section{El carácter heteráquico de las relaciones}

Las relaciones horizontales deben prevalecer sobre las verticales.

\section{El consenso}

Las alternativas se construyen en consenso con el grupo y van a incidir en el tipo de relaciones que el grupo requiere para poder moverse y movilizar eficientemente sus ideas.

\section{Emocionalidad/racionalidad}

No sólo se construye desde lo racional, también desde los deseos, los intereses y los gustos.

\section{La transparencia para proceder}

Compartir con los participantes los objetivos de la consultoría: ¿por qué estamos aquí? (consultores y 
participantes) ¿Cuál es nuestra pretensión? ¿Cómo vamos a lograr lo que queremos? ¿Comparten los propósitos? ¿Desean incorporar nuevos propósitos o les gustaría modificar algunos de los propuestos? ¿Cómo nos invitaron? ¿Qué diría nuestra institución de nuestra participación? Estas son algunas de las inquietudes iniciales que se comparten con el grupo, además de ir señalando cómo se van a mover los consultores y el grupo, para dejar claro desde el comienzo un principio de transparencia en el proceso; sin este principio, las personas pueden sentirse utilizadas y asumir posiciones diferentes de las de construir colectiva, coherente, consecuente y concertadamente las alternativas de cambio (Estupiñán, 2006).

Las anteriores reglas contribuyen a la consolidación de escenarios que garantizan a las partes espacios transparentes, sólidos y desprevenidos, que permiten un desenvolvimiento libre y democrático, y que invitan al diálogo como parte del reconocimiento a la acción mediadora por los contendientes.

En este contexto, el trabajo del orientador mediador consiste en crear las condiciones para administrar la conversación y ayudar a los participantes a trazar su itinerario, su propia solución al conflicto. Esta es una invitación al diálogo, a la comprensión y a la escucha activa, a las reflexiones y a las conversaciones con la experiencia propia y la de los otros. Los caminos son, en sí mismos, reflejo de lo que consideran que puede enlazarse, los puentes que pueden tender, lo que es similar y lo que es diferente, lo que está más allá de lo aceptable o lo posible.

Finalmente, la pedagogía para la convivencia, como la mediación alternativa, no tiene otra perspectiva que aceptar el conflicto como una oportunidad de cambio, ya que la visión positiva del conflicto trae consigo no solamente cocrear una cultura del no conflicto, sino que permite a los contendientes administrar responsablemente los conflictos propios y allanarse hacia vías de soluciones concretas, reales y satisfactorias para las partes, trátese de individuos, organizaciones o comunidades.
Privilegiar la pedagogía para la convivencia en la educación como práctica cotidiana en el aula permite proveer tempranamente herramientas y destrezas para la solución de conflictos, incentiva todas las formas de participación social, mejora la calidad de la comunicación, desarrolla la posibilidad de una formación ética y ciudadana, ayuda a prevenir la violencia, propicia prácticas democráticas, incentiva la coconstrucción de contextos colaborativos, ayuda no sólo a prevenir la violencia como medio para dirimir los conflictos, sino también al desarrollo de los jóvenes como una oportunidad de cambio para la sociedad.

La mediación transformadora es de gran utilidad por cuanto facilita la confrontación, propicia la coparticipación responsable, permite considerar y reconocer la singularidad de cada participante en el conflicto, incrementa la posibilidad latente de ganar conjuntamente, establece los puentes en común y sienta las bases para implementar las soluciones efectivas que legitimen la participación de todos los actores o grupos involucrados para resolver constructiva y colaborativamente los conflictos entre pares. Promueve así el cambio mediante la búsqueda de soluciones acordadas, concertadas y concienzudas para la construcción de nuevos contextos que se erijan como espacios de plena convivencia, respeto mutuo, solidaridad y cooperatividad, no sólo en el ámbito de la escuela, sino como práctica que se replique de manera generalizada en la sociedad.

\section{Referencias}

Bakhtin, M. M. (1986). Speech genres and other late essays (C. Emerson \& M. Holquist, comps.; V. W. McGee, trad.). Austin: University of Texas Press.

Bohm, D. (1996). (Lee Nichol, comp.), On dialogue. Londres-Nueva York: Routledge.

Bush, R.A.B. \& Folger, J.P. (1994). La promesa de la mediación. Buenos Aires: Granica. 
Colectivo Amani. (1994). Educación intercultural. Análisis y resolución de conflictos. Madrid: Popular.

Estupiñán, J. (2006). Consultoría sistémica. Un enfoque interventivo, formativo e investigativo. Bogotá: Universidad Santo Tomás.

Etxeberría, F., Esteve, J.M. \& Jordán, J.A. (2001). La escuela y la crisis social. En: P. Ortega, (coord.). Conflicto, violencia y educación. Actas del XX Seminario Interuniversitario de Teoría de la Educación. Murcia: Cajamurcia.

Gergen, K. J. (1994). Realidades y relaciones. Buenos Aires: Paidós.

Hernández, M.A. (2002). Reflexiones sobre la educación en el siglo XXI. La agresividad en la escuela. Ponencia presentada al Congreso Internacional virtual de Educación (2002). Universidad de las Islas Baleares (ISBN:847632-744-7).
Ortega, P. (2001). Presentación. En: P. Ortega (coord.) Conflicto, violencia y educación. Actas del XX Seminario Interuniversitario de Teoría de la Educación. Murcia: Cajamurcia.

Ovejero, A. (1999). Psicología social de la educación. Barcelona: Herde.

Picand, Ch. (2002). La mediación en conflictos interpersonales y de pequeños grupos. La Habana: Centro Felix Varela.

Rubin, J. Z. \& Brown, B. R. (1975). The social psychology of bargaining and negotiation. Nueva York: Academic Press.

Schnitman, D. F. (2000). Nuevos paradigmas en la resolución de conflictos. Buenos Aires: Paidós.

Uranga, M. (1997). Mediación, negociación, y habilidades para el conflicto en el marco escolar. [en llínea] http//www.gernikagogoratuz.org/artículolmireiaurangaa.html [2007, febrero 28]. 